\title{
Leptin and ghrelin levels in patients with obstructive sleep apnoea: effect of CPAP treatment
}

\author{
I.A. Harsch*, P.C. Konturek*, C. Koebnick ${ }^{\#}$, P.P. Kuehnlein*, F.S. Fuchs*, S. Pour Schahin*, \\ G.H. Wiest*, E.G. Hahn*, T. Lohmann*, J.H. Ficker*
}

Leptin and ghrelin levels in patients with obstructive sleep apnoea: effect of CPAP treatment. I.A. Harsch, P.C. Konturek, C. Koebnick, P.P. Kuehnlein, F.S. Fuchs, S. Pour Schahin, G.H. Wiest, E. G. Hahn, T. Lohmann, J.H. Ficker. C) ERS Journals Ltd 2003.

ABSTRACT: Serum leptin and ghrelin levels were investigated in patients with obstructive sleep apnoea (OSA) syndrome before and during continuous positive airways pressure (CPAP) treatment and compared with body mass index (BMI)matched controls without OSA.

Male patients $(n=30)$ with OSA (apnoea/hypopnoea index $=58 \pm 16, B M I=32.6 \pm$ $5.3 \mathrm{~kg} \cdot \mathrm{m}^{-2}$ ) underwent CPAP treatment. Fasting leptin and ghrelin were measured at baseline and 2 days, and in the case of leptin 2 months after initiation of treatment.

Baseline plasma ghrelin levels were significantly higher in OSA patients than in controls. After 2 days of CPAP treatment, plasma ghrelin decreased in almost all OSA patients $(n=9)$ to levels that were only slightly higher than those of controls $(n=9)$. Leptin levels did not change significantly from baseline after 2 days of CPAP treatment, but were higher than in the control group. After 8 weeks, leptin levels decreased significantly, although the BMI of the patients showed no change. The decrease in leptin levels was more pronounced in patients with a BMI $<30 \mathrm{~kg} \cdot \mathrm{m}^{-2}$.

These data indicate that the elevated leptin and ghrelin levels are not determined by obesity alone, since they rapidly decreased during continuous positive airways pressure therapy.

Eur Respir J 2003; 22: 251-257.
* Medical Dept I, Friedrich-Alexander University of Erlangen-Nuremberg, Erlangen and \#German Institute of Human Nutrition, Dept of Intervention Studies, Bergholz-Rehbruecke, Germany.

Correspondence: I.A. Harsch, Medical Dept I, Friedrich-Alexander University ErlangenNuremberg, Division of Respiratory Medicine and Division of Endocrinology and Metabolism, Ulmenweg 18, D-91054 Erlangen, Germany.

Fax: 4991318535025

E-mail: igor.harsch@med1.imed.uni-erlangen.de

Keywords: Continuous positive airways pressure ghrelin

leptin

obesity

obstructive sleep apnoea syndrome

sleep

Received: January 292003

Accepted after revision: April 72003
Obstructive sleep apnoea (OSA) is a common disorder affecting $2-4 \%$ of the adult population [1]. OSA is strongly associated with obesity. In a recent study involving 773 patients with OSA, only $6.5 \%$ had a normal body mass index (BMI), while $75.2 \%$ were obese $\left(\mathrm{BMI} \geqslant 30 \mathrm{~kg} \cdot \mathrm{m}^{-2}\right)$ [2]. Patients with OSA appear to be more likely to put on weight than equally obese subjects without OSA [3]. The mechanisms underlying this phenomenon remain obscure. Recently, a number of authors have speculated that changes in serum leptin levels or leptin-receptor insensitivity may be involved in the pathogenesis of progressive obesity in patients with OSA [4]. Leptin has been found to reduce appetite and simultaneously to increase respiratory drive in an animal model $[5,6]$. In humans, the situation may be expected to be more complicated. In recent studies, fasting leptin levels in patients with OSA decreased after initiation of continuous positive airways pressure (CPAP) treatment [7, 8]. However, those leptin measurements were performed on awake individuals in the morning, when the respiratory situation was normalised, so that any linkage between leptin levels and respiratory effects is difficult in this setting. Furthermore, leptin levels are influenced by a multitude of factors, such as sex, body weight $[9,10]$, the presence of hypertension, or specific medications impacting on leptin levels. Diurnal and ultradian variations in serum leptin levels are further factors complicating profound insights concerning significant respiratory effects [11-13].

However, the finding that a hormone like leptin is able to cover a variety of biological functions, beyond its well-investigated role for the regulation of body weight and energy expenditure, also prompted the present authors to investigate ghrelin in OSA. Ghrelin is a more recently discovered hormone [14] that also influences appetite and energy homeostasis. Since its initial description in 1999, there is a growing body of evidence, that this 28 amino acid gut-brain peptide has a strong effect on appetite, food utilisation, body weight and body composition in both animals and humans [15]. It stimulates hunger and food intake, when administered intravenously in healthy humans [16]. Human obesity is associated with decreased ghrelin levels that increase after weight reduction [17]. Such findings identify ghrelin, to some extent, as an antagonist of leptin. In analogy with leptin, with its multitude of effects beyond feeding behaviour and energy homeostasis discovered in recent years, it seems reasonable to assume additional effects of ghrelin beyond those already known. Hints on other functions have been the demonstration of growth hormone $(\mathrm{GH})$ secretagogue-binding sites in peripheral tissues, such as the brain and the lung [18, 19], and the observation that ghrelin promotes slow-wave sleep in males [20].

Against this background, the authors decided to measure the plasma ghrelin and leptin levels of patients with OSA before and during CPAP treatment in comparison with equally obese controls without OSA, and to investigate whether those hormones are influenced by a normalisation of sleep and nocturnal respiration during CPAP treatment. 


\section{Patients and methods}

\section{Subjects}

Thirty untreated obese male patients with severe OSA and 30 healthy controls were studied. The OSA group was recruited from a population of patients referred to the sleep laboratory for initiation of CPAP therapy. To confirm the diagnosis, all patients in the OSA group underwent standard polysomnography in the sleep laboratory as well as standard pulmonary function testing. Male patients aged $\geqslant 35 \mathrm{yrs}$, with a BMI $\geqslant 25 \mathrm{~kg} \cdot \mathrm{m}^{-2}$ and an apnoea/hypopnoea index (AHI) of at least $30 \mathrm{~h} \cdot$ sleep $^{-1}$ were included. Individuals with central sleep apnoea or Cheyne Stokes' respiration, clinically manifest nasal obstruction, severe chronic obstructive pulmonary disease (COPD) or asthma (forced expiratory volume in one second FEV $1<70 \%$ predicted) were excluded. Additional characteristics of the patients and the controls are shown in tables 1 and 2 .

For the control group, 30 healthy, age- and BMI-matched male volunteers were examined with an ambulatory screening device (Somnocheck $\AA$; Weinmann, Hamburg, Germany) [21]. Only male subjects aged $\geqslant 35 \mathrm{yrs}$, with a BMI $\geqslant 25 \mathrm{~kg} \cdot \mathrm{m}^{-2}$, and an AHI $<5 \mathrm{~h} \cdot$ sleep $^{-1}$ were included. An all-male group was investigated to rule out the potential confounding factor of sex due to higher leptin levels in females [10, 22]. Of the 37 individuals initially screened for the control group, seven had an $\mathrm{AHI} \geqslant 5$, and had to be excluded, leaving 30 as controls.

Individuals with any other condition that may possibly influence leptin or ghrelin levels, such as chronic inflammatory intestinal diseases or rheumatoid disorders, other chronic inflammatory diseases, malignant tumours, dysfunction of the thyroid gland, diabetes mellitus and cardiac disease (New York Heart Association Functional Class $\geqslant$ II ), as well as treatment with corticosteroids [23-25], sex hormones [26] and $\beta$-blockers [27] were excluded from both groups, as were longterm fasting individuals [28]. Since ghrelin is a stomachderived hormone, patients with gastric disease or prior gastric surgery were excluded from the study. Nine patients in the OSA group were hypertensive and receiving calcium antagonists $(n=5)$, angiotensin-converting enzyme (ACE) inhibitors $(n=4)$ or angiotensin-II antagonists $(n=1)$. Only one patient within the control group was hypertensive and was receiving a calcium antagonist and an ACE inhibitor.

\section{Sleep studies}

Diagnostic polysomnographies were performed in the sleep laboratory by trained sleep laboratory technicians as described

Table 1.-Parameters of the nine obstructive sleep apnoea (OSA) patients and nine controls (ghrelin group)

\begin{tabular}{|c|c|c|c|c|c|}
\hline & \multicolumn{2}{|c|}{ OSA patients } & \multirow[t]{2}{*}{ Controls } & \multicolumn{2}{|c|}{ p-value } \\
\hline & Baseline & 2 Days of therapy & & At baseline & At 2 days $\#$ \\
\hline Age yrs & $54 \pm 2$ & & $49 \pm 2$ & 0.140 & \\
\hline $\mathrm{BMI} \mathrm{kg} \cdot \mathrm{m}^{-2}$ & $33.0 \pm 1.4$ & & $33.9 \pm 1.3$ & 0.644 & \\
\hline Body fat $\%$ & $34.5 \pm 1.6$ & & $35.2 \pm 1.4$ & 0.730 & \\
\hline AHI $\cdot h$ sleep $^{-1}$ & $55 \pm 10$ & $5 \pm 2$ & $3 \pm 1$ & $<0.001$ & 0.102 \\
\hline ODI $\cdot h^{-1}$ & $55 \pm 4$ & $7 \pm 2$ & $7 \pm 2$ & $<0.001$ & 0.867 \\
\hline Basal $\mathrm{O}_{2}$ saturation $\%$ & $92 \pm 1$ & $96 \pm 1$ & $95 \pm 1$ & 0.018 & 0.349 \\
\hline Minimal $\mathrm{O}_{2}$ saturation $\%$ & $67 \pm 3$ & $85 \pm 2$ & $85 \pm 2$ & $<0.001$ & 0.953 \\
\hline Average $\mathrm{O}_{2}$ saturation $\%$ & $85 \pm 2$ & $91 \pm 1$ & $89 \pm 1$ & 0.025 & 0.047 \\
\hline Arousals n & $61 \pm 5$ & $18 \pm 1$ & & & \\
\hline ESS & $12.2 \pm 0.7$ & $5.0 \pm 0.3$ & $5.6 \pm 0.4$ & $<0.001$ & 0.310 \\
\hline Plasma insulin $\mu \mathrm{E} \cdot \mathrm{mL}^{-1}$ & $11.1 \pm 1.5$ & $11.1 \pm 1.1$ & $14.7 \pm 1.6$ & 0.129 & 0.090 \\
\hline Somatomedin $\mathrm{C} n g \cdot \mathrm{mL}^{-1}$ & $131 \pm 16$ & $146 \pm 17$ & $148 \pm 15$ & 0.465 & 0.924 \\
\hline Plasma leptin $\mathrm{ng} \cdot \mathrm{mL}^{-1}$ & $9.2(7.3-11.5)$ & $10.1(8.0-12.9)$ & $8.5(6.7-10.8)$ & 0.824 & 0.611 \\
\hline Plasma ghrelin $\mathrm{pg} \cdot \mu \mathrm{L}^{-1}$ & $57.9(46.0-72.9)$ & $19.7(15.0-26.6)$ & $10.8(7.6-15.3)$ & 0.001 & 0.204 \\
\hline
\end{tabular}

Data are presented as mean \pm SEM or geometrical mean (geometrical SEM) unless otherwise stated. BMI: body mass index; AHI: apnoea/hypopnoea index; ODI: oxygen desaturation index; $\mathrm{O}_{2}$ : oxygen; ESS: Epworth Sleepiness Scale. ${ }^{\#}$ : controls versus OSA.

Table 2. - Parameters of obstructive sleep apnoea (OSA) patients and healthy controls $(n=30)$

\begin{tabular}{|c|c|c|c|c|c|c|c|}
\hline & \multirow[t]{2}{*}{ Controls } & \multicolumn{3}{|c|}{ OSA patients } & \multicolumn{3}{|c|}{ p-value } \\
\hline & & Baseline & 2 Days & 8 Weeks & At baseline $\mathrm{A}^{\#}$ & At 2 days ${ }^{\#}$ & At 8 weeks $\#$ \\
\hline Subjects $n$ & 30 & 30 & 30 & 13 & & & \\
\hline Age yrs & $51 \pm 1$ & $52 \pm 2$ & & & 0.540 & & \\
\hline $\mathrm{BMI} \mathrm{kg} \cdot \mathrm{m}^{-2}$ & $30.6 \pm 0.6$ & $32.6 \pm 1.0$ & $32.6 \pm 1.0$ & $32.4 \pm 1.8$ & 0.096 & 0.096 & 0.383 \\
\hline Body fat \% & $30.6 \pm 0.6$ & $33.5 \pm 1.1$ & $33.5 \pm 1.1$ & $32.6 \pm 2.2$ & 0.135 & 0.135 & 0.583 \\
\hline AHI $\cdot h$ sleep $^{-1}$ & $2 \pm 1$ & $58 \pm 16$ & $6 \pm 1$ & $4 \pm 1$ & $<0.001$ & 0.003 & 0.333 \\
\hline ODI $\cdot h^{-1}$ & $4 \pm 1$ & $58 \pm 3$ & $7 \pm 2$ & $4 \pm 2$ & $<0.001$ & 0.210 & 0.904 \\
\hline Basal $\mathrm{O}_{2}$ saturation $\%$ & $95 \pm 1$ & $92 \pm 1$ & $96 \pm 1$ & $97 \pm 1$ & 0.003 & 0.060 & 0.003 \\
\hline Minimal $\mathrm{O}_{2}$ saturation $\%$ & $87 \pm 1$ & $68 \pm 2$ & $87 \pm 2$ & $88 \pm 2$ & $<0.001$ & 0.993 & 0.666 \\
\hline Average $\mathrm{O}_{2}$ saturation $\%$ & $90 \pm 1$ & $85 \pm 1$ & $92 \pm 1$ & $93 \pm 1$ & 0.003 & 0.003 & 0.003 \\
\hline Arousals n & & $62 \pm 3$ & $21 \pm 1$ & $19 \pm 1$ & & & \\
\hline ESS & $5.1 \pm 0.3$ & $11.0 \pm 0.4$ & $5.1 \pm 0.2$ & $5.1 \pm 0.2$ & $<0.001$ & 0.927 & 0.785 \\
\hline Plasma leptin $\mathrm{ng} \cdot \mathrm{mL}^{-1}$ & $4.4(3.6-5.4)$ & $12.7(10.7-14.9)$ & $13.1(11.1-15.5)$ & $6.8(4.7-9.7)$ & $<0.001$ & $<0.001$ & 0.660 \\
\hline
\end{tabular}

Data are presented as mean \pm SEM or geometrical mean (geometrical SEM) unless otherwise stated. BMI: body mass index; AHI: apnoea/hypopnoea index; ODI: oxygen desaturation index; $\mathrm{O}_{2}$ : oxygen; ESS: Epworth Sleepiness Scale. ${ }^{\#}$ : controls versus OSA patients. 
previously [29]. All variables were recorded on a computer (SleepLab, Jaeger and Toennies, Hoechburg, Germany), and included electroencephalography (C4/A1, C3/A2), bilateral electrooculography, submental electromyography, nasal airflow measured by oronasal thermistors, snoring detected by microphone, electrocardiography, thoracic and abdominal movements measured by uncalibrated inductive plethysmography, and oxyhaemoglobin saturation using a finger oxymeter (Microspan (R 3040G; Jaeger and Toennies).

Obstructive apnoeas were defined as the absence of oronasal airflow for $\geqslant 10 \mathrm{~s}$. Hypopnoeas were defined as a reduction in thoracoabdominal movement amplitude to $\leqslant 60 \%$ of the preceding stable baseline for $\geqslant 10 \mathrm{~s}$ [30] together with a drop in oxygen $\left(\mathrm{O}_{2}\right)$ saturation of $\geqslant 4 \%$. The mean number of apnoeas and hypopnoeas per hour of sleep was calculated as the AHI. Sleep parameters were determined using the criteria of RECHTSCHAFFEN and KAHLES [31], and arousals were defined in accordance with the guidelines of the American Sleep Disorders Association [32]. The data were analysed manually by one of the authors.

All individuals in the control group underwent polygraphy

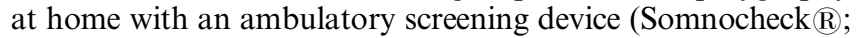
Weinmann). This unit is provided with a belt that is applied round the patient's chest. A combined airflow/snoring sensor is applied to the patient's upper lip. This sensor picks up the airflow as a summed signal derived from three thermistors, and also the sounds of snoring via an integrated microphone. A pulse oxymeter for recording $\mathrm{O}_{2}$ saturation and pulse rate is attached to a finger. A body position sensor is integrated within the basic unit. The unit was attached to the volunteers by a trained sleep laboratory technician in their homes before they retired. This device has recently been validated and showed a very high sensitivity when used as a screening device for OSA [21]. The data were analysed manually by the same sleep lab technician who read the polysomnography recordings of the study group. For this purpose the data were

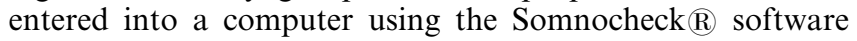
(version 1.02). Apnoeas were defined as an absence of oronasal flow for $\geqslant 10 \mathrm{~s}$. Hypopnoeas were defined as a discernible reduction in respiratory airflow accompanied by a decrease in $\mathrm{O}_{2}$ saturation $\geqslant 4 \%$. For the calculation of the AHI the total number of respiratory events was related to the overall duration of the measurement.

\section{Continuous positive airways pressure therapy}

For CPAP treatment a standard CPAP device Somnotron 4® (Weinmann) was used. Manual titration of the CPAP pressure was performed in the sleep laboratory under polysomnographic control by a trained sleep laboratory technician. For each patient, the minimum effective pressure at which most of the apnoeas, hypopnoeas and snoring were abolished in all body postures and all stages of sleep was established. Starting from an initial $0.4 \mathrm{kPa}$ (4 mbars), the pressure was increased in steps of $0.1 \mathrm{kPa}(1 \mathrm{mbar})$ at intervals of $\geqslant 5 \mathrm{~min}$ when obstructive events (apnoeas, hypopnoeas or snoring) occurred. If no further events occurred during the next $30 \mathrm{~min}$, the pressure was then reduced every $10 \mathrm{~min}$ in steps of $0.1 \mathrm{kPa}$ (1 mbar) until they re-occurred, whereupon the pressure was increased once more in the manner described above [29]. On the second night of CPAP, the patients were treated with the minimum effective pressure established during the previous night.

\section{Serum leptin measurements}

Blood samples for leptin measurements were taken at 07:15 h after an overnight fast. The samples were collected in ethylendiamine tetraacetic acid (EDTA)-coated polypropylene tubes kept on ice, centrifuged immediately at $1,800 \times g$ for $20 \mathrm{~min}$ at $0^{\circ} \mathrm{C}$, and the clear plasma supernatant was then stored until plasma leptin levels were measured using an enzymelinked immunosorbent assay (ELISA) kit (IBL ELISA kit ${ }^{\mathrm{TM}}$; IBL Inc., Hamburg, Germany). All plasma samples were analysed in duplicate and in the same batch.

\section{Serum ghrelin measurements}

Blood samples for ghrelin measurements were collected in vacutainers with EDTA at the same time and under the same conditions as for leptin. Collection and processing were performed as described for leptin. A generic plasma extraction procedure was performed using the elution solvents $1 \%$ trifluoroacetic acid (buffer A) and 60\% acetonotrile (buffer B). After the extraction procedure, ghrelin was measured using a radioimmunoassay (RIA) kit (Peninsula Laboratories, Inc., San Carlos, CA, USA). Lipaemic sera showing implausible ghrelin values in a preliminary analysis were excluded. The intra- and interassay coefficients of variation were $<10 \%$.

\section{Study design}

In both OSA patients and controls, baseline blood samples for the measurement of serum leptin and ghrelin, insulin and somatomedin C (also known as insulin-like growth factor-1), were obtained at $07: 15 \mathrm{~h}$ on the morning after the diagnostic night. At this time, the patients had been awake for $\sim 1 \mathrm{~h}$. All patients, as well as the controls, had had a standard evening meal of $\sim 500 \mathrm{kcal}$ at 19:00 $\mathrm{h}$ before the diagnostic nights and the treatment nights. After the evening meal, they were only allowed to drink mineral water. Total body fat was estimated using the formula of GARROW and WEBSTER [33]. In the OSA group, a CPAP titration was performed as described and during the second treatment night CPAP was applied at the effective pressure level. On the morning following the second night of CPAP treatment, another blood sample of leptin and ghrelin was taken at 07:15 h. A further blood sample of leptin was obtained after 8 weeks of effective and regular CPAP treatment at 07:15 h. At all time points, the Epworth Sleepiness Scale (ESS) was assessed [34]. The built-in data stores of the CPAP devices were read out, the number of days of use within the past 42-day period established, and the mean duration of use per night calculated. CPAP treatment was considered "regular" if the device had been used on $\geqslant 35$ of 45 nights for a minimum of $3 \mathrm{~h}$ each night.

The study protocol was examined and approved by the Ethics Committee of the Friedrich-Alexander University, ErlangenNuremberg. All patients gave their written informed consent.

\section{Data collection and statistical analysis}

All data are presented as mean \pm SEM to illustrate differences between groups. To normalise the distribution, plasma leptin and ghrelin levels were log-transformed and are shown as geometric means and with geometric SE. Baseline characteristics were compared using pooled or separate variances t-test or separate-variances t-tests for equality of means where applicable. Homogeneity of variances was tested by Levene's Test for Equality of Variances.

Plasma leptin levels after log transformation and differences during therapy were compared by analysis of covariance with and without repeated measurement design with simultaneous adjustment for BMI. All potentially confounding variables 
(age, AHI, oxygen desaturation index (ODI), hypertension, ESS, adherence to CPAP therapy) were tested in preliminary models, and on the basis of these results only BMI and ESS remained in the final models. In analysis of variance models estimating effects on differences in plasma leptin concentrations during therapy, ESS score and the presence of hypertension remained in the final models. In addition, patients were divided into two groups in accordance with the World Health Organization criteria for overweight patients: a BMI $\leqslant 29.99 \mathrm{~kg} \cdot \mathrm{m}^{-2}$ (grade I overweight) were compared with patients with a $\mathrm{BMI}>30 \mathrm{~kg} \cdot \mathrm{m}^{-2}$ (overweight grades II and III).

The linear relationships between plasma ghrelin, as a dependent variable, and its potential predictors, as independent variables, were estimated using multiple linear regression analysis with backward elimination of independent variables. Removal criteria were a significance level $>0.15$ and a tolerance level $<0.3$.

\section{Results}

Fasting ghrelin levels were analysed in a subgroup of OSA patients $(n=9)$ before and 2 days after initiation of CPAP treatment and compared with those of nine BMI-matched controls. Parameters of the OSA patients and the control groups, together with leptin and ghrelin levels are shown in table 1. Basal, minimal and average minimal $\mathrm{O}_{2}$ saturation were significantly lower in OSA patients than in controls. After 2 days of treatment, basal and minimal $\mathrm{O}_{2}$ saturation were similar to those of controls, the average minimal $\mathrm{O}_{2}$ saturation was slightly higher in OSA patients. The individual course of ghrelin levels in the nine OSA patients compared with the nine controls is shown in figure 1 . The means of ghrelin are given in comparison with the 13 patients with leptin measured before, 2 days and 8 weeks after onset of CPAP treatment in figure 2. Fasting plasma insulin did not change after 2 days of CPAP therapy but were slightly lower in OSA patients than in controls (table 1). In contrast, somatomedin $\mathrm{C}$ levels increased significantly after 2 days of treatment $(\mathrm{p}=0.014)$.

Baseline plasma ghrelin levels differed significantly between OSA patients and controls $(\mathrm{p}=0.001)$. After 2 days of treatment, plasma ghrelin levels decreased in all OSA patients

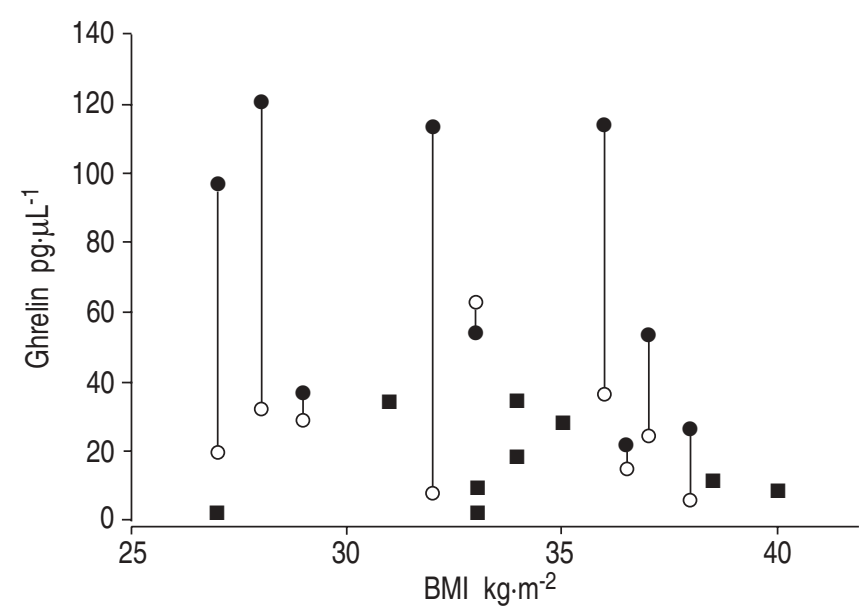

Fig. 1.-Individual fasting ghrelin levels $(n=9)$ in comparison with nine body mass index (BMI)-matched controls. After 2 days of treatment, plasma ghrelin levels decreased in all obstructive sleep anoea (OSA) patients except one and are only slightly higher than those of the controls. $\square$ : control; 0 : OSA (untreated); $\bigcirc$ : OSA (2 days of continuous positive airways pressure)

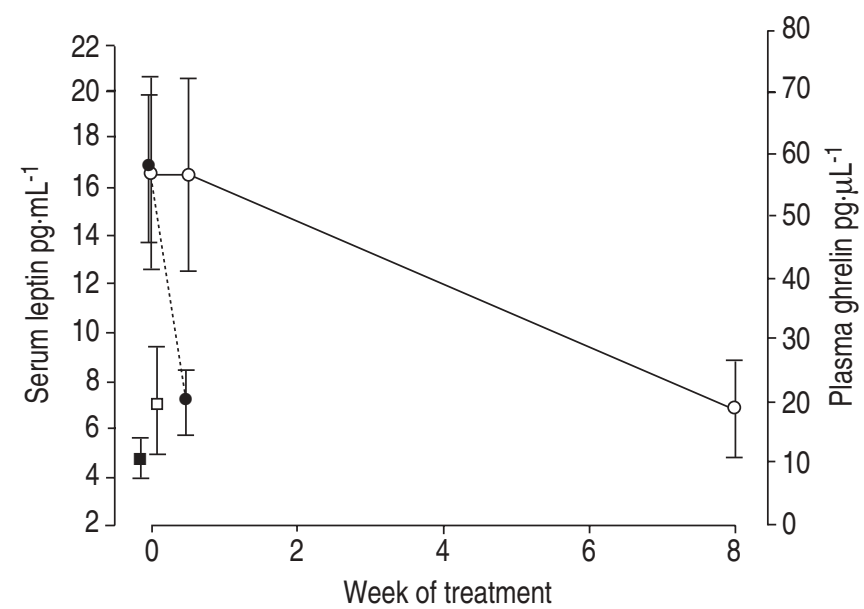

Fig. 2.-Fasting leptin levels $(\bigcirc)$ in obstructive sleep apnoea (OSA) patients $(n=13)$ before, 2 days and 8 weeks after initiation of continuous positive airway pressure (CPAP) treatment. The leptin values (given as geometric means and geometric SEM) before and after 2 days of CPAP treatment differ significantly in comparison with controls $(\square)$ and the leptin values after 8 weeks of CPAP treatment. Fasting ghrelin levels in nine OSA patients (O) and controls ( $\boldsymbol{\square})$ are also shown. The baseline ghrelin levels differ significantly between OSA patients (baseline versus 2 days of CPAP treatment) and controls.

except one and were only slightly higher than those of controls.

In a multivariate regression analysis, BMI and total body fat were shown as predictors of ghrelin levels in both OSA patients and controls (table 3 ). The explanatory power of average minimal and minimal $\mathrm{O}_{2}$ saturation, serum leptin, presence of hypertension, ESS score and fasting plasma insulin differed between OSA patients and controls. The minimal $\mathrm{O}_{2}$ saturation was a significant predictor in OSA patients but not in controls. In OSA patients ghrelin levels were higher in the presence of hypertension. They also increased with increasing plasma insulin. In controls plasma ghrelin was predicted by plasma leptin levels and ESS score (table 3).

In a multivariate regression analysis the change of plasma ghrelin after 2 days of treatment was positively related to baseline ghrelin levels $(\mathrm{p}=0.043)$, presence of hypertension $(\mathrm{p}=0.005)$, minimal $\mathrm{O}_{2}$ saturation $(\mathrm{p}=0.023)$ and ESS score $(\mathrm{p}=0.001)$ at baseline. No relationship could be found between changes of plasma ghrelin and BMI, body fat, baseline leptin levels, somatomedin $\mathrm{C}$ or fasting plasma insulin.

Parameters of the initial 30 patients with OSA and the 30 controls are shown in table 2. The plasma leptin concentrations were higher in OSA patients before therapy than in controls $(p<0.001)$, even after adjustment for BMI $(p<0.001)$ and ESS ( $\mathrm{p}=0.080)$. Plasma leptin concentrations were further analysed after 2 days in all patients and after 8 weeks of treatment in a smaller subgroup of 13 patients. This subgroup did not differ from the overall group in any of the baseline parameters, e.g. age, BMI, plasma leptin, AHI, ESS. After 2 days of CPAP, plasma leptin concentrations in OSA patients remained unchanged, but after 8 weeks of treatment a significant decrease in plasma leptin was observed $(p=0.004)$ after adjusting for hypertension $(\mathrm{p}=0.013)$ and $\operatorname{ESS}(\mathrm{p}=0.029)$ simultaneously. After 8 weeks of therapy, plasma leptin concentrations in OSA patients were not significantly different from plasma leptin concentrations in a subgroup of 13 healthy controls matched for BMI ( $\mathrm{p}=0.660)$.

In the 13 patients studied after 8 weeks of CPAP treatment, no significant differences were found between initial and the 8 week BMI $(p=0.290)$. The treatment-associated decrease in 
Table 3. - Multivariate relationships between characteristics of the obstructive sleep apnoea (OSA) patients and plasma ghrelin concentrations in all subjects

\begin{tabular}{|c|c|c|c|c|c|c|}
\hline \multirow[t]{2}{*}{ Independent variable ${ }^{\#}$} & \multicolumn{3}{|c|}{$\begin{array}{l}\text { Dependent variable log } \\
\text { plasma ghrelin }{ }^{\uparrow} \text { for OSA patients }\end{array}$} & \multicolumn{3}{|c|}{$\begin{array}{l}\text { Dependent variable log } \\
\text { plasma ghrelin }{ }^{\uparrow} \text { for controls }\end{array}$} \\
\hline & $\beta$ & SEE & p-value & $\beta$ & SEE & p-value \\
\hline Intercept & 8.525 & 1.576 & 0.012 & -4.342 & 1.977 & 0.116 \\
\hline $\mathrm{BMI} \mathrm{kg} \cdot \mathrm{m}^{-2}$ & -0.742 & 0.229 & 0.048 & -0.504 & 0.070 & 0.006 \\
\hline Total body fat $\%$ & 0.591 & 0.199 & 0.059 & 0.395 & 0.060 & 0.007 \\
\hline Hypertension & 0.609 & 0.160 & 0.032 & & & \\
\hline $\mathrm{Log}$ plasma leptin $\mathrm{pg} \cdot \mathrm{mL}^{-1}$ & & & & 1.860 & 0.209 & 0.003 \\
\hline Average minimal $\mathrm{O}_{2}$ saturation $\%$ & & & & 0.065 & 0.025 & 0.076 \\
\hline Minimal $\mathrm{O}_{2}$ saturation $\%$ & 0.037 & 0.010 & 0.031 & & & \\
\hline ESS & & & & 0.175 & 0.055 & 0.050 \\
\hline Plasma insulin $\mu \mathrm{E} \cdot \mathrm{mL}^{-1}$ & 0.030 & 0.012 & 0.056 & & & \\
\hline
\end{tabular}

BMI: body mass index; $\mathrm{O}_{2}$ : oxygen; ESS: Epworth Sleepiness Scale. ${ }^{\#}$ : variables excluded from the model were age, basal $\mathrm{O}_{2}$ saturation, apnoea/ hypopnoea index, oxygen desaturation index, somatomedin $C$; $: \beta$-coefficients of multiple linear regression analysis and standard error of the estimate (SEE). $\mathrm{R}^{2}$ was 0.764 for OSA patients and 0.946 for control subjects.

serum leptin was affected by the initial weight and degree of hypertension (data not shown). The decrease in plasma leptin concentrations between baseline and treatment day 2 was similar in OSA patients with a BMI $<30 \mathrm{~kg} \cdot \mathrm{m}^{-2}$ and OSA patients with a BMI $>30 \mathrm{~kg} \cdot \mathrm{m}^{-2}$. After 8 weeks of treatment the decrease in plasma leptin was more pronounced in OSA patients with a BMI $<30 \mathrm{~kg} \cdot \mathrm{m}^{-2}$ than in those with a BMI $>30 \mathrm{~kg} \cdot \mathrm{m}^{-2}(\mathrm{p}=0.021)$. The decrease in plasma leptin was slightly greater in hypertensive than in normotensive OSA patients $(\mathrm{p}=0.053)$. The adherence to CPAP therapy of OSA patients was $5.1 \pm 0.2 \mathrm{~h} \cdot$ night $^{-1}$. Due to the small range of adherence no effect of adherence to CPAP therapy on the decrease in plasma leptin during therapy could be observed.

Baseline leptin correlated significantly with BMI ( $r=0.744$, $\mathrm{p}<0.001)$ and body fat content $(\mathrm{r}=0.729, \mathrm{p}<0.001)$. Only weak correlations with AHI ( $\mathrm{r}=0.421)$, ODI ( $\mathrm{r}=0.527)$, arousal index $(\mathrm{r}=0.462)$ and the average minimal $\mathrm{O}_{2}$ saturation $(\mathrm{r}=-0.287)$ were found. After adjustment for BMI, these correlations were even weaker $(r=0.082,0.199,0.154$ and $0.004 ; \mathrm{p}=0.673$, $0.291,0.423$ and 0.984 , respectively).

\section{Discussion}

Ghrelin and leptin are both hormones with well-investigated functions concerning body composition, energy homeostasis and feeding behaviour in animal models and humans. A central role of leptin as a neurohumoral modulator of central respiratory mechanisms and lung function has furthermore been established in animal models [35].

Ghrelin is the natural ligand of the GH secretagogue receptor and to some extent a hormone with leptin-antagonistic properties. Possible interactions between ghrelin and respiratory mechanisms have not been investigated as yet. Ghrelin levels were investigated in a subgroup of patients and baseline plasma ghrelin levels were found to be significantly higher in OSA patients than in BMI-matched controls, but decreased to levels similar to those of obese patients without OSA after 2 days of treatment. This decrease occurs within a period of time too short for any significant changes of body fat mass or visceral fat accumulation (VFA). This finding is surprising, since ghrelin and leptin seem to exhibit a similar behaviour under the circumstances described, although they have antagonistic properties in terms of energy balance at least. Furthermore, since insulin is a physiological modulator of plasma ghrelin [36] and insulin resistance is a typical finding in obese patients with OSA [37], an increase in ghrelin may have been expected. Direct interactions could not be established between plasma ghrelin and plasma insulin or somatomedin $\mathrm{C}$, the latter an important mediator of $\mathrm{GH}$ action.

Multivariate analysis revealed plasma ghrelin to be correlated with minimal $\mathrm{O}_{2}$ saturation in the patient group. However, the patient number is low and the study was not designed to investigate interactions between ghrelin and indices of sleepdisordered breathing. Several interactions between OSA and hormonal factors, such as insulin resistance [38] and disturbances of the hypothalamic-pituitary-adrenal axis [39], are known. Thus, further studies are mandatory to clarify whether the decrease of ghrelin under CPAP treatment is due to interactions with respiration physiology, or whether the normalisation of ghrelin is merely the expression of a reconstitution of the complex neurohumoral network regulating sleep and respiratory function caused by the normalisation of nocturnal sympathetic drive and hypoxia. One further unsolved question is whether changes in total ghrelin do reflect changes in the biologically active or inactive peptide, since commercially available ghrelin RIA kits detect both octanoylated and nonoctanoylated ghrelin

Growing insight into the functions of leptin also indicates a possible role of elevated leptin as a homeostatic response to the pathophysiological situation (e.g. nocturnal arousals, nocturnal hypoventilation) induced by OSA, which decreases with the control of OSA by CPAP therapy [7, 8]. No significant changes in fasting leptin 2 days after initiation of CPAP treatment were found, but a significant decrease in leptin levels after 2 months of CPAP treatment with no significant changes in body weight were confirmed.

Computed tomographies were not conducted to differentiate between VFA and subcutaneous fat. VFA is regarded as a better predictor of coronary heart disease than the BMI [40]. CHIN et al. [8] demonstrated significant decreases in VFA after 6 months of CPAP treatment, even in OSA patients with no loss of body weight. They furthermore demonstrated a significant decrease of leptin after 3-4 days of CPAP treatment, which is too short a time interval to have significant effects on body fat or its distribution. Such a decrease may be more readily explained, for example, by effects of CPAP on sympathetic activation [41].

A number of authors have tried to establish a direct relationship between serum leptin and the severity of OSA, usually determined via the AHI $[42,43]$. In a recent study, serum leptin concentrations (log-transformed) were found to be significantly correlated with the AHI ( $r=0.39)$, but failed to reach significance after correction for BMI and body fat in a group with numerous comorbidities [44]. The latter finding is in accordance with the present results showing a positive 
correlation between serum leptin and the AHI ( $r=0.4)$, which is lost after correction for the BMI. The frequency of arterial hypertension in the current patient group was high in comparison with the nonhypertensive patients in the studies from Phillips et al. [42] and MANZElla et al. [43] and a possible explanation may be that the present patient group and those of SCHÄFER et al. [44] are too different in terms of comorbidities, also possibly confounding the relationship between AHI and serum leptin levels.

The AHI, reflecting the mean number of apnoeas and hypopnoeas per hour of sleep, cannot be considered a parameter that adequately reflects the severity of all aspects of OSA. For instance, vigilance, daytime performance and cardiovascular effects of OSA are known to be only weakly correlated with AHI. One further problem has to be addressed; indices of sleep-disordered breathing are measured in sleeping patients, whereas the leptin and ghrelin studies were determined in patients already awake. This bias was also present concerning leptin in preceeding studies, thus, making further investigations with nocturnal profiles of leptin and ghrelin mandatory.

In conclusion, these data support findings suggesting that leptin is a hormonal factor affected by continuous positive airways pressure treatment in obstructive sleep apnoea patients independently of changes in body weight. Plasma ghrelin levels are also significantly higher in obstructive sleep apnoea patients than in body mass index-matched controls, and decreased significantly during continuous positive airways pressure treatment. With reservations dictated by the small number, it may be speculated that ghrelin, as well as leptin, is influenced by continuous positive airways pressure treatment due to effects unknown as yet, which should be investigated in further studies.

Acknowledgements. The authors would like to thank M. Mueller for organisational support and P. Michaeli for help with the graphic presentation.

\section{References}

1. Strollo PJ, Rogers RM. Obstructive sleep apnea. $N$ Engl J Med 1996; 334: 99-104.

2. Smith R, Ronald J, Delaive K, Walld R, Manfreda J, Kryger MH. What are obstructive sleep apnea patients being treated for prior to this diagnosis? Chest 2002; 121: 164-172.

3. Phillips BG, Hisel TM, Kato M, et al. Recent weight gain in patients with newly diagnosed obstructive sleep apnea. J Hypertens 1999; 17: 1297-1300.

4. Caro JF, Kolaczynski JW, Nyce MR, et al. Decreased cerebrospinal-fluid/serum leptin ratio in obesity: a possible mechanism for leptin resistance. Lancet 1996; 348: 159-161.

5. O'Donnell CP, Tankersley CG, Polotsky VP, Schwartz AR, Smith PL. Leptin, obesity, and respiratory function. Respir Physiol 2000; 119: 163-170.

6. Tankersley CG, O'Donnell C, Daood MJ. Leptin attenuates respiratory complications associated with the obese phenotype. J Appl Physiol 1998; 85: 2261-2269.

7. Ip MS, Lam KS, Ho C, Tsang KW, Lam W. Serum leptin and vascular risk factors in obstructive sleep apnea. Chest 2000; 118: 569-571.

8. Chin K, Shinizu K, Nakamura T, et al. Changes in intraabdominal visceral fat and serum leptin levels in patients with obstructive sleep apnea syndrome following nasal continuous positive airway pressure therapy. Circulation 1999; 100: 706-712.

9. Considine RV, Sinha MK, Heiman ML, et al. Serum immunoreactive leptin concentrations in normal-weight and obese humans. N Engl J Med 1996; 334: 292-295.

10. Saad MF, Riad-Gabriel MG, Khan A, et al. Diurnal and ultradian rhythmicity of plasma leptin: effects of gender and adiposity. J Clin Endocrinol Metab 1998; 83: 453-459.

11. Sinha MK, Ohannesian JP, Heimann ML, et al. Nocturnal rise of leptin in obese, and non-insulin-dependent diabetes mellitus subjects. J Clin Invest 1996; 97: 1344-1347.

12. Sinha MK, Sturis J, Ohannesian J, et al. Ultradian oscillations of leptin secretions in humans. Biochem Biophys Res Commun 1996; 228: 733-738.

13. Mantzoros CS, Ozata M, Negrao, et al. Synchronicity of frequently sampled thyrotropin (TSH) and leptin concentrations in healthy adults and leptin-deficient subjects: Evidence for possible partial TSH regulation by leptin in humans. $J$ Clin Endocrinol Metab 2001; 86: 3284-3291.

14. Kojima M, Hosoda H, Date Y, Nakazato M, Matsuo H, Kangawa K. Ghrelin is a growth-hormone-releasing acylated peptide from stomach. Nature 1999; 402: 656-660.

15. Shintani M, Ogawa $\mathrm{Y}$, Ebihara $\mathrm{K}$, et al. Ghrelin, an endogenous growth hormone secretagogue, is a novel orexigenic peptide that antagonizes leptin action through the activation of hypothalamic neuropeptide Y/Y1 receptor pathway. Diabetes 2001; 50: 227-232.

16. Wren AM, Seal LJ, Cohen MA, et al. Ghrelin enhances appetite and increases food intake in humans. $J$ Clin Endocrinol Metab 2002; 86: 5992-5997.

17. Tschöp M, Weyer C, Tataranni PA, Devanarayan V, Ravussin E, Heimann ML. Circulating ghrelin levels are decreased in human obesity. Diabetes 2001; 50: 707-709.

18. Guan XM, Yu H, Palyha OC, McKee KK, Feighner SD, Sirinathsihgnji DJ. Distribution of mRNA encoding the growth hormone receptor in brain and peripheral tissues. Brain Res Mol Brain Res 1997; 48: 23-29.

19. Papotti M, Ghe C, Cassoni P, et al. Growth hormone secretagogue binding sites in peripheral human tissues. $J$ Clin Endocrinol Metab 2000; 85: 3803-3807.

20. Weikel JC, Wichniak A, Ising M, et al. Ghrelin promotes slow wave sleep in young normal men. Am J Physiol Endocrinol Metab 2002; 284: E407-E415.

21. Ficker JH, Wiest GH, Wilpert J, Fuchs FS, Hahn EG Evaluation of a portable recording device (Somnocheck) for use in patients with suspected obstructive sleep apnoea. Respiration 2001; 68: 307-312.

22. Rosenbaum M, Nicholson M, Hirsch $\mathrm{J}$, et al. Effects of gender, body composition, and menopause on plasma concentrations of leptin. J Clin Endocrinol Metab 1996; 81: 3424 3427.

23. Miell JP, Englaro P, Blum WF. Dexamethasone induces an acute and sustained rise in circulating leptin levels in normal human subjects. Horm Metab Res 1996; 28: 704-707.

24. Larsson H, Ahren B. Short-term dexamethasone treatment increases plasma leptin independently of change in insulin sensitivity in healthy women. J Clin Endocrinol Metab 1996; 81: 4428-4432.

25. Papaspyrou-Rao S, Schneider SH, Peteraen RN, Fried SK. Dexamethasone increases leptin expression in humans in vitro. J Clin Endocrinol Metab 1997; 82: 2542-2547.

26. Rosenbaum M, Nicholson M, Hirsch J, Heymsfield SB, Gallager D, Chu F. Suppressive effects of androgens on plasma leptin levels while estrogen-progesteron induce higher levels. J Clin Endocrinol Metab 1996; 81: 3424-3427.

27. Donahoo WT, Jensen TR, Yost TJ, Eckel RH. Isoproterenol and beta 3-receptor agonists reduce leptin mRNA expression and circulating levels. J Clin Endocrinol Metab 1997; 82: 4319-4343.

28. Kolaczynski JW, Ohannesian JW, Considine RV, Marco CC, Caro JF. Responses of leptin to short-term fasting and refeeding in humans. Diabetes 1996; 45: 1511-1515.

29. Ficker JH, Wiest GH, Lehnert G, Hahn EG. Evaluation of an auto-CPAP device for treatment of obstructive sleep apnoea. Thorax 1998; 53: 643-648.

30. Gould GA, Whyte GB, Airlie MAA, Catterall JR, Shapiro CM, Douglas NJ. The sleep hypopnoea syndrome. Am Rev Respir Dis 1988; 137: 895-898. 
31. Rechtschaffen A, Kahles A. A manual of standardized terminology, techniques and scoring system for sleep stages of human subjects. Los Angeles, Public Health Service, US Government Printing, 1968.

32. Bonnet M, Charley D, Carskadon MA. EEG arousals: scoring rules and examples. Sleep 1992; 15: 174-184.

33. Garrow JS, Webster J. Quetelet's index (W/H2) as a measure of fatness. Int J Obesity 1985; 9: 147-153.

34. Johns MW. A new method for measuring daytime sleepiness: The Epworth Sleepiness Scale. Sleep 1991; 14: 540-545.

35. O'Donnell CP, Schaub CD, Haines AS, et al. Leptin prevents respiratory depression in obesity. Am $J$ Respir Crit Care Med 1999; 159: 1477-1484.

36. Saad MF, Bernaba B, Hwu C-M, et al. Insulin regulates plasma ghrelin concentration. J Clin Endocrinol Metab 2002; 87: 3997-4000.

37. Grunstein RR. Metabolic aspects of sleep apnea. Sleep 1996; 19: S218-S220.

38. Ip MS, Lam B, Ng MMT, Lam WK, Tsang KWT, Lam KSL.
Obstructive sleep apnea is independently associated with insulin resistance. Am J Respir Crit Care Med 2003; 165: 670-676.

39. Luboshitzky R, Aviv A, Hefetz A, et al. Decreased pituitarygonadal secretion in men with obstructive sleep apnea. $J$ Clin Endocrinol Metab 2002; 87: 3394-3398.

40. Bjorntorp P. Body fat distribution, insulin resistance, and metabolic diseases. Nutrition 1997; 13: 795-803.

41. Snitker P, Pratley RE, Nicholson M, Tartarini PA, Ravussin E. Relationship between muscle sympathetic nerve activity and plasma leptin concentration. Obes Res 1997; 5: 338-340.

42. Phillips BG, Kato M, Narkiewicz K, et al. Increases in leptin levels, sympathetic drive, and weight gain in obstructive sleep apnea. Am J Physiol Heart Circ Physiol 2000; 279: 234-237.

43. Manzella D, Prillo M, Razzino T, et al. Soluble leptin receptor and insulin resistance as determinant of sleep apnea. Int $J$ Obesity 2002; 26: 370-375.

44. Schäfer H, Pauleit D, Sudhop T, Gouni-Berthold I, Ewig S, Berthold HK. Body fat distribution, serum leptin, and cardiovascular risk factors in men with obstructive sleep apnea. Chest 2002; 122: 829-839. 